University of Nebraska - Lincoln

DigitalCommons@University of Nebraska - Lincoln

June 2006

\title{
Ferroelectric behavior in nominally relaxor lead lanthanum zirconate titanate thin films prepared by chemical solution deposition on copper foil
}

Taeyun Kim

North Carolina State University, Raleigh, tkim@pearne.com

Jacqueline N. Hanson

North Carolina State University, Raleigh

Alexei Gruverman

University of Nebraska-Lincoln, agruverman2@unl.edu

Angus I. Kingon

North Carolina State University, Raleigh, angus_kingon@brown.edu

S. K. Streiffer

Center for Nanoscale Materials and Materials Science Division, Argonne National Laboratory, Argonne, Illinois

Follow this and additional works at: https://digitalcommons.unl.edu/physicsgruverman

Part of the Physics Commons

Kim, Taeyun; Hanson, Jacqueline N.; Gruverman, Alexei; Kingon, Angus I.; and Streiffer, S. K., "Ferroelectric behavior in nominally relaxor lead lanthanum zirconate titanate thin films prepared by chemical solution deposition on copper foil" (2006). Alexei Gruverman Publications. 21.

https://digitalcommons.unl.edu/physicsgruverman/21

This Article is brought to you for free and open access by the Research Papers in Physics and Astronomy at DigitalCommons@University of Nebraska - Lincoln. It has been accepted for inclusion in Alexei Gruverman Publications by an authorized administrator of DigitalCommons@University of Nebraska - Lincoln. 


\title{
Ferroelectric behavior in nominally relaxor lead lanthanum zirconate titanate thin films prepared by chemical solution deposition on copper foil
}

\author{
Taeyun Kim, ${ }^{\text {a) }}$ Jacqueline N. Hanson, Alexei Gruverman, and Angus I. Kingon \\ Department of Materials Science and Engineering North Carolina State University, Raleigh, North Carolina \\ 27695 and Department of Physics, North Carolina State University, Raleigh, North Carolina 27695 \\ S. K. Streiffer \\ Center for Nanoscale Materials and Materials Science Division, Argonne National Laboratory, Argonne, \\ Illinois 60439
}

(Received 26 February 2006; accepted 13 May 2006; published online 29 June 2006)

\begin{abstract}
We demonstrate that $\left(\mathrm{Pb}_{0.9} \mathrm{La}_{0.1}\right)\left(\mathrm{Zr}_{0.65} \mathrm{Ti}_{0.35}\right)_{0.975} \mathrm{O}_{3}$ (PLZT) (10/65/35) thin films that have a nominally relaxor composition and that are deposited by chemical solution deposition onto copper foil show polarization hysteresis. Ferroelectric domain switching and a shift in Curie temperature are also observed. This is in contrast to the non-hysteretic behavior of films with identical composition prepared on $\mathrm{Pt} / \mathrm{SiO}_{2} / \mathrm{Si}$ substrates. This suggests that the mismatch in coefficient of thermal expansion between PLZT and copper induces a compressive strain in the PLZT during cooling after high temperature crystallization under low $p \mathrm{O}_{2}$, and causes an out-of-plane polarization. (C) 2006 American Institute of Physics. [DOI: 10.1063/1.2217254]
\end{abstract}

Lead zirconate titanate (PZT) thin films have been widely investigated for a variety of applications including nonvolatile memory ${ }^{1}$ and piezoelectric/pyroelectric devices. ${ }^{2}$ To tailor ferroelectric, piezoelectric, and dielectric properties of PZT thin films, many dopants have been investigated, including $\mathrm{La}$ for enhanced reliability characteristics.,4 $\left(\mathrm{Pb}_{1-x} \mathrm{La}_{x}\right)\left(\mathrm{Zr}_{0.65} \mathrm{Ti}_{0.35}\right)_{1-x / 4} \mathrm{O}_{3}$ (PLZT) $(100 x / 65 / 35,100 x$ $\geqslant 7)$ compositions show relaxor characteristics, and are very attractive for electromechanical, electro-optics, and dielectric applications. ${ }^{5,6}$ It was reported that high quality PZT thin films can be synthesized by chemical solution deposition (CSD) directly on copper foil by performing the required high temperature processing under controlled $p \mathrm{O}_{2}$, thus demonstrating the potential of high permittivity thin films on low cost base metal foil for ferroelectric and piezoelectric applications. ${ }^{7,8}$ This letter extends these previous studies to PLZT films on copper foil, specifically for dielectric applications such as embedded capacitors.

PLZT (10/65/35) thin films were prepared by CSD, using lead acetate trihydrate, zirconium propoxide, titanium isopropoxide, and acetic acid with propyl alcohol as a solvent. ${ }^{7}$ Excess $\mathrm{Pb}(15 \mathrm{~mol} \%)$ was added to the starting precursors to compensate for the loss during high temperature crystallization. Copper foil (35 $\mu \mathrm{m}$ thick, PLSP, Oak Mitsui) was used as substrate. Seven layers of PLZT solution were applied to get the final thickness of $\sim 620 \mathrm{~nm}$. For the initial three layers, samples were spun on (at $3000 \mathrm{rpm}$ for $30 \mathrm{~s})$, dried $\left(250^{\circ} \mathrm{C}\right.$ for $\left.5 \mathrm{~min}\right)$ in air, and then pyrolyzed at $400{ }^{\circ} \mathrm{C}$ for 15 min under a reducing atmosphere using mixture of nitrogen [300 SCCM (SCCM denotes standard cubic centimeter per minute at STP)] and forming gas $\left(1 \% \mathrm{H}_{2}\right.$ in $\mathrm{N}_{2}$, 4 SCCM) through water bubbler. The subsequent (four to seven) layers were dried at $300{ }^{\circ} \mathrm{C}$. To minimize film cracking, additional pyrolysis at $400{ }^{\circ} \mathrm{C}$ for $15 \mathrm{~min}$ was undertaken after the sixth layer was dried, still under reducing atmosphere. Final crystallization was done at $700{ }^{\circ} \mathrm{C}$ for 15 min using mixture of nitrogen (300 SCCM) and forming

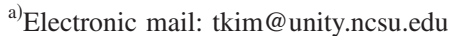

gas $\left(1 \% \mathrm{H}_{2}\right.$ in $\left.\mathrm{N}_{2}, 2 \mathrm{SCCM}\right)$ which corresponds to $p \mathrm{O}_{2}$ $\approx 10^{-16} \mathrm{~atm}$. Through-thickness metal-insulator-metal capacitors were formed by depositing $100 \mathrm{~nm}$ thick $\mathrm{Cu}$ or $\mathrm{Pt}$ top electrodes by dc magnetron sputtering through a shadow mask. X-ray diffraction (Bruker AXS D-5000, Germany) was used for phase identification. Dielectric and ferroelectric properties were measured using an impedance analyzer (Hewlett-Packard HP4192A) and ferroelectric tester (Radiant Technologies RT66A). Temperature-dependent dielectric properties were obtained from 248 to $540 \mathrm{~K}$ using a cryogenic temperature stage (MMR Technologies). Impedance analysis was performed at $100 \mathrm{kHz}$ at an oscillation level of $1.6 \mathrm{kV} / \mathrm{cm}$. An atomic force microscope (Thermomicroscopes (P-R) with Keithley 236 source measure unit was used to apply switching voltage pulses to the sample via a Ti-Pt coated Si cantilever ( $5 \mathrm{~N} / \mathrm{m}$ force constant, MikroMasch). The modulation voltage ( $3 \mathrm{~V} \mathrm{rms}$ at $10 \mathrm{kHz}$ ) was applied to detect the piezoelectric response.

It is known that heavy La substitution ( $\geqslant 7 \mathrm{~mol} \%$ ) into PZT decreases the $c / a$ ratio of the unit cell to near unity, approaching a pseudocubic structure. ${ }^{9}$ A slim hysteresis loop and relaxor permittivity response normally result. However, clear hysteresis in the permittivity-field response typical of a ferroelectric is found, and zero field permittivity and dielectric loss were 710 and 0.06, respectively [Fig. 1(a)]. Hysteresis loops for the PLZT films on copper, had coercive field $\left(E_{c}\right)$ and remanent polarization $\left(P_{r}\right)$ of $45 \mathrm{kV} / \mathrm{cm}$ and $18 \mu \mathrm{C} / \mathrm{cm}^{2}$, while slim loop with $P_{r}$ of $4.5 \mu \mathrm{C} / \mathrm{cm}^{2}$ (at $250 \mathrm{kV} / \mathrm{cm}$ ) was measured for PLZT films on $\mathrm{Pt} / \mathrm{SiO}_{2} / \mathrm{Si}$ [Fig. 1(b)]. The x-ray diffraction pattern for PLZT thin film on copper foil (Fig. 2) shows only randomly oriented polycrystalline perovskite phase, together with copper. No other phases (pyrochlore, cupric oxide) were detected, suggesting that there should be no impact of either impurity phases or interfacial reactions on the properties. ${ }^{7,8}$ Moreover considering the polarization responses for PLZT $(10 / 65 / 35)$ thin films on $\mathrm{Pt} / \mathrm{SiO}_{2} / \mathrm{Si}$ [Fig. 1(b)], processed in parallel with PLZT thin films on copper, we would suggest that the ferro- 


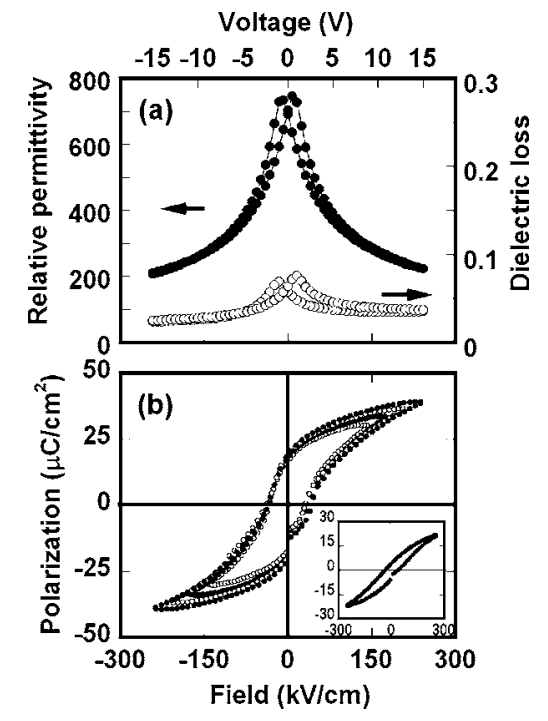

FIG. 1. Field dependent (a) permittivity and dielectric loss and (b) polarization for PLZT (10/65/35) thin films on copper foil. The inset in Fig. 1(b) is for PLZT $(10 / 65 / 35)$ thin films on $\mathrm{Pt} / \mathrm{SiO}_{2} / \mathrm{Si}$, processed in parallel with PLZT (10/65/35) thin films on copper.

electric responses in Fig. 1 are related to the underlying copper substrate.

Figure 3 shows piezoresponse force microscopy (PFM) results for PLZT thin films on copper foil. Topography images demonstrate that the PLZT films were composed of spherical grains with $130-200 \mathrm{~nm}$ size. Positive and negative $15 \mathrm{~V}$ dc biases were applied to concentric areas of 2 $\times 2$ and $1 \times 1 \mu \mathrm{m}^{2}$, respectively, through the scanning tip to investigate switching characteristics. Piezoresponse images clearly reveal bright/dark regions associated with opposite piezoelectric constants and polarity. Both piezoelectric hysteresis loop and piezoresponse images again indicate that the PLZT thin films, despite its nominally relaxor composition for bulk ceramics, ${ }^{9}$ can show normal ferroelectric responses, depending on the underlying substrates.

Several reports have shown the effect of strain and film/substrate misfit on the thermodynamic properties of single domain ferroelectric thin films on single crystal substrates. ${ }^{10,11}$ Considering the difference in thermal expansion coefficients between copper [16.5 ppm (Ref. 12)] and the extrapolated cubic parent phase of PLZT [ $\sim 4$ ppm (Ref. 13)], it is likely that a significant in-plane compressive stress develops in the PLZT thin films on copper foil, during the cooling step after high temperature crystallization. These strains might contribute to inducing out-of-plane polarization and the observed ferroelectric responses.

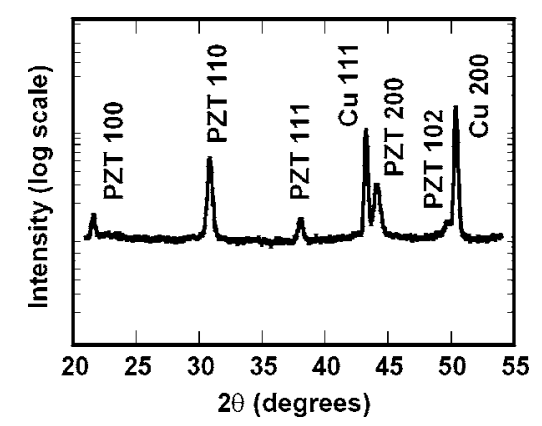

FIG. 2. X-ray diffraction pattern for PLZT (10/65/35) thin film on copper foil.
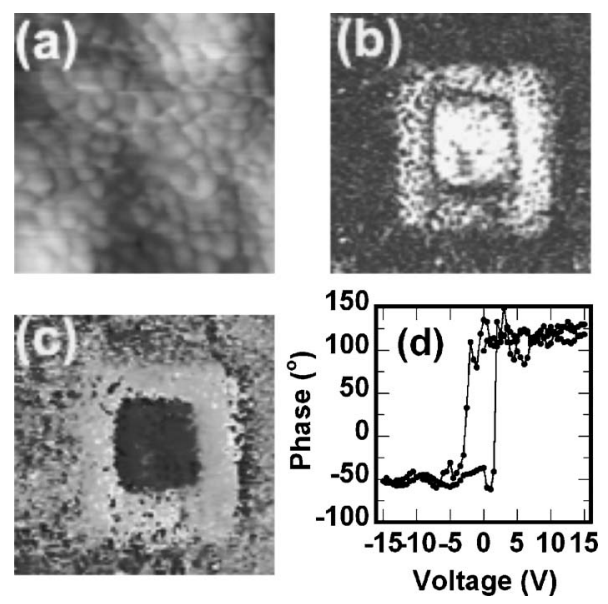

FIG. 3. (a) Topographic $\left(2 \times 2 \mu \mathrm{m}^{2}\right)$, (b) amplitude $\left(4 \times 4 \mu \mathrm{m}^{2}\right)$, (c) phase $\left(4 \times 4 \mu \mathrm{m}^{2}\right)$ images, and (d) piezoelectric phase loop of PLZT (10/65/35) thin films on copper foil.

To obtain an order-of-magnitude estimate of the effect of compressive stress on the PLZT behavior, it is useful to calculate the shift in $T_{C}$ of a nominally electrostrictive sample given the expected stress levels. Due to the absence of materials data for PLZT, PLZT (10/65/35) behavior is approximated as similar to rhombohedral PZT $(0 / 60 / 40){ }^{14}$ The shift in $T_{C}$ for the (001) orientation is therefore calculated as ${ }^{15,16}$

$$
\theta_{\text {out of plane }}=\frac{\theta-4 \varepsilon_{0} C(\Delta \alpha) T^{\prime}\left[Q_{12} /\left(S_{11}+S_{12}\right)\right]}{1-4 \varepsilon_{0} C(\Delta \alpha)\left[Q_{12} /\left(S_{11}+S_{12}\right)\right]} .
$$

Calculations from Eq. (1) suggest that the $T_{C}$ of PZT (60/40) thin films might be shifted upward by approximately $100 \mathrm{~K}$ when copper is used as the underlying substrate, given the temperature excursion and thermal expansion mismatches. This implies that there is a significant driving force to impose ferroelectric order onto the otherwise relaxor composition, and generate an out-of-plane polarization, while the random polycrystalline texture is consistent with the somewhat sheared hysteresis loops.

The applicability of this calculation is supported by the temperature-dependent dielectric properties for PLZT $(10 / 65 / 35)$ thin films shown in Fig. 4, where a broad peak in permittivity is apparent at approximately $465 \mathrm{~K}$. Compared to the PLZT thin films on Pt (Ref. 17) and bulk PLZT (Ref. 5) with identical composition, where the maximum in permittivity ranges from 353 to $391 \mathrm{~K}$, it is clear that $T_{C}$ is shifted upward by $74-110 \mathrm{~K}$ for PLZT $(10 / 65 / 35)$ thin films on copper.

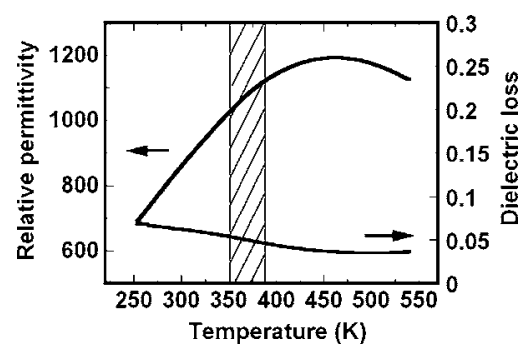

FIG. 4. Temperature dependence of dielectric properties for PLZT $(10 / 65 / 35)$ thin films on copper foil. The shadow area shows the $T_{C}$ regions for bulk PLZT (Ref. 5) and films on $\mathrm{Pt} / \mathrm{SiO}_{2} / \mathrm{Si}$ (Ref. 17). 
It should be pointed out in considering this mechanism, however, that the temperature at which peak permittivity occurs has not been found to be shifted for $\mathrm{BaTiO}_{3}$ thin films on copper foil, ${ }^{18}$ although stress development and the resulting electromechanical response are expected to be similar. This seeming inconsistency between PLZT and $\mathrm{BaTiO}_{3}$ remains to be investigated, although differences in microstructure and internal stress distribution between the PLZT and $\mathrm{BaTiO}_{3}$ films are likely.

In summary, clear ferroelectric response was reproducibly observed in polycrystalline PLZT (10/65/35) thin films deposited directly on copper foil. Hysteresis loops indicate $E_{c}$ and $P_{r}$ of $45 \mathrm{kV} / \mathrm{cm}$ and $18 \mu \mathrm{C} / \mathrm{cm}^{2}$, respectively. Zero field permittivity and dielectric loss were found to be 710 and 0.06. PFM confirmed nominally relaxor PLZT $(10 / 65 / 35)$ can show ferroelectric domain switching. Both thermodynamic estimates and measurement of $T_{C}$ shift suggest that the out-of-plane polarizations may result from inplane compressive strain generated by thermal expansion mismatch between the PLZT thin film and copper foil during cooling after high temperature crystallization.

The authors would like to thank J. Ihlefeld for the cold stage measurement. Work performed at ANL was supported by the U.S. Department of Energy, Basic Energy SciencesMaterials Sciences, through contract W-31-109-ENG-38.
${ }^{1}$ H. N. Al-Shareef, O. Auciello, and A. I. Kingon, J. Appl. Phys. 77, 2146 (1995).

${ }^{2}$ S. Trolier-McKinstry and P. Muralt, J. Electroceram. 12, 7 (2004).

${ }^{3}$ R. E. Jones, Jr., P. D. Maniar, J. O. Olowolafe, A. C. Campbell, and C. J. Mogab, Appl. Phys. Lett. 60, 1022 (1992).

${ }^{4}$ T. Toshihiko and D. A. Payne, J. Am. Ceram. Soc. 77, 1242 (1994).

${ }^{5}$ G. H. Haertling and C. E. Land, J. Am. Ceram. Soc. 54, 1 (1971).

${ }^{6}$ D. Dimos, W. L. Warren, M. B. Sinclair, B. A. Tuttle, and R. W. Schwartz, J. Appl. Phys. 76, 4305 (1994).

${ }^{7}$ A. I. Kingon and S. Srinivasan, Nat. Mater. 4, 233 (2005).

${ }^{8}$ M. D. Losego, L. H. Jimison, J. F. Ihlefeld, and J.-P. Maria, Appl. Phys. Lett. 86, 172906 (2005).

${ }^{9}$ G. H. Haertling, Ferroelectrics 75, 25 (1987).

${ }^{10}$ A. K. Tagantsev, N. A. Pertsev, P. Muralt, and N. Setter, Phys. Rev. B 65, 012104 (2001)

${ }^{11}$ N. A. Pertsev, A. G. Zembilgotov, S. Hoffmann, R. Waser, and A. K. Tagantsev, J. Appl. Phys. 85, 1698 (1999).

${ }^{12}$ D. R. Lide, CRC Handbook of Chemistry and Physics, 86th ed. (CRC, Boca Raton, FL, 2005).

${ }^{13}$ M. Yokosuka and M. Marutake, Jpn. J. Appl. Phys., Part 1 25, 981 (1986).

${ }^{14}$ M. J. Haun, Z. Q. Zhuang, E. Furman, S. J. Jang, and L. E. Cross, Ferroelectrics 99, 45 (1989).

${ }^{15}$ S. K. Streiffer, C. B. Basceri, C. B. Parker, Se. E. Lash, and A. I. Kingon, J. Appl. Phys. 86, 4565 (1999).

${ }^{16}$ N. A. Pertsev, V. G. Kukhar, H. Kohlstedt, and R. Waser, Phys. Rev. B 67, 054107 (2003).

${ }^{17}$ G. H. Haertling, Integr. Ferroelectr. 3, 207 (1993).

${ }^{18}$ J. F. Ihlefeld, J.-P. Maria, and W. Borland, J. Mater. Res. 20, 2838 (2005). 